\title{
FAKTOR-FAKTOR YANG MEMPENGARUHI KEMAMPUAN PENYULUH KESEHATAN MASYARAKAT TERHADAP PELAKSANAAN CAKUPAN PROGRAM PROMOSI KESEHATAN DI KOTA PAREPARE
}

\section{Factors that Influence the Ability of Health Care Community to Implementation of the Coverage of Health Promotion Program In Parepare}

\author{
Armiati, Usman, Abidin \\ (Program Studi Kesehatan Masyarakat Fakultas Ilmu Kesehatan Universitas Muhammadiyah \\ Parepare) \\ (armiati.xiirpli@gmail.com, 082310230828)
}

\begin{abstract}
ABSTRAK
Promosi kesehatan merupakan upaya yang bersifat promotif (peningkatan) sebagai perpaduan dari upaya preventif (pencegahan), kuratif (pengobatan), dan rehabilitatif (pemulihan) dalam rangkaian upaya kesehatan yang komprehensif. Untuk melaksanakan upaya kesehatan wajib tersebut di puskesmas diperlukan tenaga fungsional penyuluh kesehatan masyarakat untuk mengelola promosi kesehatan di puskesmas secara profesional dan mampu untuk mengelola serta menyelenggarakan pelayanan yang bersifat promotif dan preventif. penelitian ini bertujuan untuk menunujukkan apakah tingkat pengetahuan dan keterampilan penyuluh kesehatan masyarakat berpengaruh terhadap pelaksanaan cakupan program promosi kesehatan di Kota Parepare. Penelitian menggunakan survei analitik dengan pendekatan cross sectional study. Waktu penelitian pada bulan Mei-Juli 2018 dengan jumlah sampel 31 petugas yang terdiri dari Dinas kesehatan dan Puskesmas se Kota Parepare. Data di analisis secara univariat dan bivariat dengan menggunakan uji ststistik uji Chi-Square. Hasil penelitian menunjukkan bahwa ada pengaruh tingkat pengetahuan $(\mathrm{p}=0,053)$, keterampilan $(\mathrm{p}=0,000)$ terhadap pelaksanaan cakupan program promosi kesehatan di Kota Parepare. Berdasarkan hasil tersebut, disarankan Perlunya disiplin ilmu terutama pada bidang promosi kesehatan agar lebih memudahkan petugas mengelolah program promosi kesehatan yang ada di Dinas Kesehatan ataupun puskesmas di Kota Parepare.
\end{abstract}

Kata kunci : Penyuluh kesehatan masyarakat, tingkat pengetahuan, keterampilan , program promosi kesehatan

\section{ABSTRACT}

Health promotion is an effort that promotes (increases) as a combination of preventive (prevention), curative (treatment), and rehabilitative (recovery) as an efforts in comprehensive series of health. To carry out this compulsory health effort at the puskesmas, functional health educators are needed to manage health promotion in health centers in a professional manner, able to manage and organize promotive and preventive services. This study aims to show whether the level of knowledge and skills of public health educators influence to the implementation of the coverage health promotion programs in the Parepare. The study used an analytical survey with a cross sectional approach. The study was conducted in May-July 2018 with a total sample 31 officers consisting of the Health Office and Puskesmas in Parepare. Data were analyzed by univariate and bivariate using Chi-Square statistical test. The results showed that there was an 
influence of the level of knowledge $(p=0.053)$, skills $(p=0.000)$ on the implementation of the coverage of health promotion programs in Parepare. Based on these results, it is recommended for disciplines, especially in for the health promotion, so that it is easier for officers to manage health promotion programs in the Health Service or health centers in Parepare.

Keywords : public health extension, knowledge level, skills, health promotion program. 


\section{PENDAHULUAN}

Seiring dengan perkembangan ilmu dan teknologi khususnya dalam bidang kesehatan, sangat diperlukannya upayaupaya sosialisasi maupun peningkatan pengetahuan tentang kesehatan, dari transformasi pengetahuan tersebut tidak terlepas semuanya dengan metode, strategi, dan penggunaan media dalam promosi kesehatan. Promosi kesehatan merupakan upaya yang bersifat promotif (peningkatan) sebagai perpaduan dari upaya preventif (pencegahan), kuratif (pengobatan), dan rehabilitatif (pemulihan) dalam rangkaian upaya kesehatan yang komprehensif . ${ }^{1}$

Dengan kebijaksanaan dan strategi ini, perencanaan dan pelaksanaan pembangunan di sektor harus mampu mempertimbangkan dampak negatif dan positif terhadap sektor kesehatan, baik bagi individu, keluarga maupun masyarakat. Di sektor kesehatan sendiri upaya kesehatan akan lebih mengutamakan upaya-upaya preventif dan promotif yang proaktif, tanpa mengabaikan upaya kuratif dan rehabilitatif. Dasar pandangan baru dalam pembangunan kesehatan ini disebut "paradigma sehat". Pembangunan kesehatan bertujuan meningkatkan kesadaran, kamauan, dan kemampuan hidup sehat bagi setiap penduduk agar dapat mewujudkan derajat kesehatan yang optimal. Derajat kesehatan merupakan salah satu faktor yang sangat berpengaruh pada kualitas sumber daya manusia. SDM yang sehat akan lebih produktif dan meningkatkan daya saing manusia. ${ }^{1}$

Puskesmas wajib menggerakkan dan memberdayakan masyarakat agar berperan aktif dalam penyelenggaraan setiap upaya kesehatan, terutama agar dalam berperilaku hidup bersih dan sehat. Oleh karna itu, upaya promosi kesehatan puskesmas membantu masyarakat agar mampu melaksanakan perilaku hidup bersih dan sehat (PHBS). Untuk melaksanakan upaya kesehatan wajib tersebut di puskesmas diperlukan tenaga fungsional penyuluh kesehatan masyarakat (PKM) untuk mengelola promosi kesehatan di puskesmas secara profesional dan mampu untuk mengelola serta menyelenggarakan pelayanan yang bersifat promotif dan preventif . ${ }^{2}$

Permasalahan sumber daya manusia atau tenaga kesehataan di Dinas Kesehatan dan Puskesmas dalam melaksanakan promosi kesehatan adalah, dimana masih kurangnya tenaga yang terampil dalam penyuluh kesehatan masyarakat. Disamping itu petugas kesehatan yang ada juga melaksanakan tugas yang lain diluar tugas pokok dan fungsinya ${ }^{3}$

Program promosi kesehatan dan pemberdayaan masyarakat di Kota Parepare yaitu pengembangan media promosi dan informasi sadar hidup sehat, pembinaan posyandu, pelatihan pertolongan pertama pada kecelakaan, sosialisasi bahaya narkoba, sosialisasi bahaya DBD, HIV/AIDS dan kanker, pengadaan da pengembangan media dan penanggulangan bahaya rokok, upaya 
promosi kesehatan dampak merokok, penyediaan data dan informasi kesehatan berbasis website dan aplikasi GIS . ${ }^{4}$

Berdasarkan profil Dinas Kesehatan Kota Parepare berdasarkan hasil pengumpulan data bidang kesehatan masyarakat tahun 2016 jumlah rumah tangga 25.853 diperoleh sebanyak 5.666 yang dipantau dan ber-PHBS diperoleh sebanyak 3.742 (66\%). Pada cakupan program pelayanan kesehatan anak usia sekolah dan remaja, dilakukan oleh tenaga kesehatan maupun peran serta tenaga terlatih lainnya seperti kader kesehatan, guru UKS dan dokter kecil. Adapun data tahun 2016 penyusun hanya mendapatkan data dari PKM Madising Na Mario dalam melakukan penjaringan anak sekolah sebesar 480 orang atau Cuma 16,4 \%. Program akses terhadap air minum berdasarkan kualitas air minum di penyelenggara air minum yang memenuhi syarat kesehatan yaitu jumlah sampel yng diperika 71 memenuhi syarat $71(100 \%)$.

\section{BAHAN DAN METODE}

Metode penelitian yang digunakan adalah penelitian survei analitik, dengan pendekatan Cross Sectional study. Lokasi yang dipilih dari penelitian ini adalah pada lingkup Dinas Kesehatan Kota Parepare yang terdiri dari 6 Puskesmas yang tersebar di Kota Parepare. Waktu penelitian pada bulan Mei-Juli 2018. Instrumen dalam penelitian yang digunakan adalah kuesioner. Adapun teknik pengumpulan data yang akan digunakan dalam penelitian ini adalah
Kuesioner (Angket), Observasi, dan Study kepustakaan yang bersumber dari data primer yang diperoleh dari hasil wawancara. Data sekunder adalah data yang diperoleh dari dokumen-dokumen data awal penelitan, data statistik profil dinas kesehatan Kota Parepare. Sampel yang diambil dari penelitian ini adalah 31 tenaga penyuluh kesehatan di Kota Parepare oleh karena itu yang menjadi objek penelitian yaitu tenaga penyuluh kesehatan masyarakat yang berjumlah 31 orang yang terdiri dari Dinas Kesehatan 4 orang, PKM Lakessi 18 orang, PKM Lompoe 2 orang, PKM Lapadde 1 orang, PKM Lumpue 1 orang, PKM Mario Na Madising 4 orang dan PKM Cempae 1 orang. Tahap yang digunakan untuk menguji hubungan antara variabel independen dan dependen adalah uji Chi-Square. Dasar pengambilan keputusan penerimaan hipotesis penelitian berdasarkan tingkat signifikan (nilai p), dimana terdapat pengaruh apabila nilai $\mathrm{p}<0,05$ dan tidak ada pengaruh apabila $\mathrm{p}>0,05$.

\section{HASIL}

Analisis karakteristik responden ini menggunakan distribusi tabel dengan data yang diperoleh dari kuesioner yang berdasarkan jabatan fungsional, umur, jenis kelamin, pendidikan terakhir dan lama kerja pada penyuluh kesehatan masyarakat di Kota Parepare. Tabel 1 dapat kita lihat bahwa jabatan fungsional mayorits promkes 41,9\%, dengan umur rata-rata 26-35 tahun 67,7\%, mayoritas jenis kelamin perempuan $87,1 \%$, 
dengan pendidikan terakhir S1 87,1\%, dengan rentan lama kerja mayoritas 6-10 tahun $45,2 \%$.

Tabel 2 dapat kita lihat distribusi analisis variabel bahwa dari 31 responden petugas penyuluh kesehatan masyarakat di Kota Parepare, yang menjawab pernyataan berdasarkan kuesioner pada distribusi tingkat pengetahun yang tergolong tinggi yaitu $77,4 \%$, keterampilan $80,6 \%$, terhadap pelaksanaan cakupan program yaitu $74,2 \%$.

Tabel 3 hasil penelitian menunjukkan bahwa dari 31 responden petugas penyuluh kesehatan masyarakat di Kota Parepare, yang menjawab pernyataan berdasarkan kuesioner pada karakteristik tingkat pengetahun yang tergolong tinggi berjumlah 24 responden yaitu $(77,4 \%)$, dan yang menjawab pernyataan berdasarkan kuesioner pada tingkat pengetahuan yang tergolong rendah berjumlah 7 responden yaitu (22,6\%). Berdasarkan analisis uji statistik chi-square diperoleh ada pengaruh tingkat pengetahuan terhadap pelaksanaan cakupan program promosi kesehatan di Kota Parepare $(\mathrm{p}=0,053)$.

Tabel 4 penelitian ini menunjukkan bahwa dari 31 responden petugas penyuluh kesehatan masyarakat di Kota Parepare, yang menjawab pernyataan berdasarkan kuesioner pada karakteristik keterampilan yang tergolong tinggi berjumlah 25 responden yaitu (80,6\%), dan yang menjawab pernyataan berdasarkan kuesioner pada keterampilan yang tergolong rendah berjumlah 6 responden yaitu $(19,4 \%)$.
Berdasarkan analisis uji statistic chi-square diperoleh ada pengaruhketerampilan terhadap pelaksanaan cakupan program promosi kesehatan di Kota Parepare $(\mathrm{p}=$ $0,000)$.

\section{PEMBAHASAN}

Pendidikan atau promosi kesehatan pada hakikatnya adalah upaya intervensi yang ditujukan pada faktor perilaku. Namun pada kenyataannya yang lain perlu intervensi pendidikan atau promosi kesehatan juga, karena perilaku juga berperan pada faktorfaktor tersebut, maka karena itu para petugas kesehatan harus mempunyai kemampuan atau pemahaman yang baik tentang pendidikan promosi kesehatan dan perilaku kesehatan .5 Namun pada kenyataannya bahwa keterbatasan sumber daya manusia dibidang promosi kesehatan masih menjadi permasalahan dimana masih kurangnya tenaga promosi kesehatan yang sesuai dengan fungsionalnya.

Hasil menelitian menunjukkan bahwa dari 31 responden petugas penyuluh kesehatan masyarakat di Kota Parepare, yang menjawab pernyataan berdasarkan kuesioner pada karakteristik tingkat pengetahun yang tergolong tinggi berjumlah 24 responden yaitu $(77,4 \%)$, dan yang menjawab pernyataan berdasarkan kuesioner pada tingkat pengetahuan yang tergolong rendah berjumlah 7 responden yaitu $(22,6 \%)$. Berdasarkan analisis uji statistik dengan menggunakan analisis uji chi-square diketahui nilai signifikasinya $0,053<0.05$ 
yang berarti terdapat pengaruh yang signifikan, maka $\mathrm{H}_{\mathrm{a}}$ diterima dan $\mathrm{H}_{0}$ ditolak. Dapat diartikan bahwa ada pengaruh tingkat pengetahuan terhadap pelaksanaan cakupan program promosi kesehatan di Kota Parepare. hal ini membuktikan bahwa tingkat pengetahuan berpengaruh terhadap pelaksanaan cakupan program promosi kesehatan karena pengetahuan yang dimiliki petugas kesehatan akan menunjang keberhasilan program.

Dari ke 6 indikator kuesioner antaranya pendidikan, persepsi, lingkungan, sosial ekonomi, kebudayaan, dan informasi. yang akan menunjang keberhasilan sebuah program yang akan dijalankan, namun berdasarkan tingkat pendidikan yang ratarata lulusan S1 hanya ada 2 petugas lulusan murni dari promkes. Hal ini yang akan menjadi penghambat bahwa keterbatasan sumber daya manusia tenaga promkes yang sesuai fungsiaonalnya namun tak dapat dipungkiri bahwa meskipun pemegang program promkes pada setiap puskesmas di Kota Parepare rata-rata tidak sesuai fungsionalnya dimana perbedaan fungsional tersebut akan mempengaruhi tingkat pengetahuan petugas

Kemampuan keterampilan adalah kemampuan psikomotorik dan teknik pelaksanaan kerja tertentu. Sedangkan kemampuan sikap adalah kesiapsiagaan mental, yang diorganisasi lewat pengalaman, yang mempunyai pengaruh tertentu kepada tanggapan seorang terhadap orang-orang, obyek, dan situasi yang berhubungan denganya. Hasil uji statistik untuk mengetahui pengaruh tingkat pengetahuan penyuluh kesehatan masyarakat terhadap pelaksanaan cakupan program promosi kesehatan di Kota Parepare dapat di lihat pada Tabel 4.

Penelitian ini menunjukkan bahwa dari 31 responden petugas penyuluh kesehatan masyarakat di Kota Parepare, yang menjawab pernyataan berdasarkan kuesioner pada karakteristik keterampilan yang tergolong tinggi berjumlah 25 responden yaitu $(80,6 \%)$, dan yang menjawab pernyataan berdasarkan kuesioner pada keterampilan yang tergolong rendah berjumlah 6 responden yaitu $(19,4 \%)$. Berdasarkan analisis uji statistik dengan menggunakan analisis uji chi-square diketahui nilai signifikasinya $0,000<0.05$ yang berarti terdapat pengaruh yang signifikan, maka $\mathrm{H}_{\mathrm{a}}$ diterima dan $\mathrm{H}_{0}$ ditolak. Dapat diartikan bahwa ada pengaruh keterampilan terhadap pelaksanaan cakupan program promosi kesehatan di Kota Parepare. Hal ini membuktikan bahwa keterampilan yang dimiliki oleh seorang petugas penyuluh kesehatan masyarakat sangat dibutuhkan dalam membawakan materi penyuluhan atau yang mencakup tentang program promosi kesehatan yang akan dilaksanakannya, baik itu penguasaan materi, penggunaan alat ataupun media. Kita ketahui bahwa pentingnya keterampilan yang dimiliki petugas tersebut akan mendorong keberhasilan sebuah program yang akan dijalankannya. 
Dari ke 3 indikator pada kuesioner antaranya motivasi, pengalaman, dan keahlian. Pada indikator diatas bahwa petugas yang memiliki motivasi yang tinggi akan mampu melaksanakan program yang akan dijalankan berpartisipasi secara penuh dan aktif guna mencapai target pencapaian yang telah ditentukan. Hal ini lah yang diinginkan dari petugas bahwa alahkan baiknya ketika pimpinan memberikan mereka peluang untuk meningkatkan pengetahuan serta keterampilan yang didapatkan dari seminar atau pelatihan tentang promkes.

\section{KESIMPULAN DAN SARAN}

Berdasarkan hasil penelitian dari faktor - faktor yang mempengaruhi kemampuan penyuluh kesehatan masyarakat terhadap pelaksanaan cakupan program promosi kesehatan di Kota Parepare dapat disimpulkan bahwa Ada pengaruh tingkat pengetahuan dan keterampilan terhadap pelaksanaan cakupan program promosi

\section{DAFTAR PUSTAKA}

1. Kholid A. Promosi Kesehatan : Dengan Pendekatan Teori Perilaku, Media, dan Aplikasinya untuk Mahasiswa dan Praktisi Kesehatan. Jakarta : Rajawali Pers; 2015.

2. Kementerian Kesehatan RI. Keputusan $\begin{array}{lrr}\text { Menteri } & \text { Kesehatan } & \text { Nomor } \\ \text { 585/MENKES/SK/V/2007 } & \text { Tentang } \\ \text { Pedoman } \quad \text { Pelaksanaan } & \text { Promosi }\end{array}$ kesehatan di Kota Parepare. Berdasarkan kesimpulan maka penulis menyarankan pihak puskesmas perlu memberikan kesempatan bagi petugas untuk mengembangkan potensi terutama dalam hal promosi kesehatan, memberikan pelatihan, mengikut sertakan seminar sehingga hal tersebut yang akan menjadi penunjang bertambahnya pengetahuan para petugas. Perlu adanya peningkatan kemampuan petugas maupun pengadaan media pendukung penyebaran informasi kesehatan dengan bantuan teknologi terutama pada penggunaan dan pemanfaatan teknologi berbasis internet. perlu adanya peningkatan keterampilan kerja setiap petugas karna hal ini sangat berpengaruh terhadap pengalaman kerja dan cara penyampaian mereka kepada masyarakat pada saat penyuluhan. Perlunya disiplin ilmu terutama pada bidang promosi kesehatan agar lebih memudahkan petugas mengelolah program promosi kesehatan yang ada di Dinas Kesehatan ataupun puskesmas di Kota Parepare

Kesehatan Di Puskesmas. Jakarta; 2015.

3. Gamrin B, Ridwan M T, Furqaan M N. Kemampuan Penyuluh Kesehatan masyarakat terhadap Cakupan Program Promosi Kesehatan Di Kabupaten Maros. Jurnal. Fakultas Kesehatan Masyarakat Universitas Hasanuddin : Makassar; 2012. 
4. Dinas Kesehatan Kota Parepare. Profil Kesehatan Kota Parepare tahun 2017. Parepare : Dinas kesehatan Kota Parepare; 2017.

5. Notoatmodjo S. Promosi Kesehatan dan Perilaku Kesehatan. Jakarta : Rineka Cipta; 2012.

6. Bastian F A. Pengaruh Kemampuan Dan Motivasi Terhadap Kinerja Karyawan Di Gtt (Gudangnya Tahu Takwa) Ud Kabupaten Kediri. Jurnal. Fakultas Ekonomi Dan Bisnis Universitas Muhammadiyah Malang : Malang; 2015.

7. Buku kerja.com. Panduan Penentuan Skoring Kriteria Kuesioner (Skala Pengukuran). [serioal online]; 2018.[Diakses 5 April 2018] di http://www.bukukerja.com/2012/10/pan duan-penentuan-skoring-

kriteria.html?m=1

8. CR Cimamora, Adelima. Pengaruh Pengetahuan petugas kesehatan Terhadap Pelaksanaan Program Promosi Kesehatan Di Puskesmas Di Kabupaten Humbang Hasundutan. Skripsi. Fakultas Kesehatan masyarakat Universitas Sumatera Utara : Medan; 2010.

9. Erpan E. Gambaran Keterampilan Pemasangan Infus Pada Perawat Vokasional Dan Perawat Profesional Rumah Sakit Pku Muhammadiyah Di Wilayah Yogyakarta. Karya Tulis Ilmiah. Fakultas Kedokteran dan Ilmu
Kesehatan Universitas Muhammadiyah Yogyakarta : Yogyakarta; 2016.

10. Gebrela B. Analisis Faktor-Faktor yang Mempengaruhi Pengeluaran Kesehatan per Kapita di Indonesia. Jurnal. Universitas Andalas : Padang; 2016.

11. Hafsa K N. Peningkatan Kemampuan Mengkritik Pada Mata Pelajaran Bahasa Indonesia Melalui Strategi Critical Incident Pada Siswa Kelas VI MI AlHidayah Benowo Surabaya. Fakultas Tarbiyah dan Keguruan Universitas Islam Negeri Sunan Ampel : Surabaya; 2016.

12. Indra K. Pengertian Pengetahuan. [serial online]; 2016. [Diakses 29 Maret 2018]

at https://materipengetahuanumum.blogsp ot.co.id/2016/10/pengertianpengetahuan.html.

13. Kementerian Kesehatan RI. Keputusan Menteri Kesehatan Nomor Hk.02.02/Menkes/52/2015 Tentang Rencana Strategis Kementerian Kesehatan Tahun 2015-2019.

Sekretariat Jenderal. Jakarta; 2015.

14. Kuron M C, A.J M.Rattu, Jane M. Pangemanan. Analisis Pelaksanaan Program Promosi Kesehatan Di Puskesmas Bahu Kecamatan Malalayang Kota Manado. Jurnal. Fakultas Kesehatan Masyarakat Universitas Sam Ratulangi Manado : Manado; 2014.

15. Lestari S, Iwan S B, Rini M. Analisis Kinerja Petugas Promosi Kesehatan 
Puskesmas Dalam Meningkatkan

Cakupan PHBS Rumah Tangga di

Wilayah Kerja Dinas Kesehatan Kota

Palembang. Jurnal. Fakultas Kesehatan

Masyarakat Universitas Sriwijaya :

Palembang; 2016.

16. Notoatmodjo S. Metodologi Penelitian Kesehatan. Jakarta : Rineka Cipta; 2012.

17. Rencana Pengembangan Tenaga Kesehatan. Undang Undang No. 36 Tahun 2009 Tentang kesehatan. Jakarta; 2009.

18. Riski A N. Strategi Integrasi Soft Skills Dalam Pembelajaran Kompetensi
Keahlian Administrasi Perkantoran Di Smk Negeri 1 Yogyakarta. Skripsi. Universitas Negeri Yogyakarta : Yogyakarta; 2012.

19. Sugiharto M. Widjiartini. Analisis Pencapaian Target Program Promosi Kesehatan Menurut Jenis Puskesmas Di Kabupaten Tulungagung. Jurnal; 2011.

20. Yulius S. Pengaruh Kemampuan Dan Motivasi Terhadap Kinerja Pegawai Bagian Sekretariat Di Dinas Pekerjaan Umum Provinsi Bengkulu. Skripsi. Fakultas Ekonomi dan Bisnis Universitas Bengkulu; 2014. 


\section{LAMPIRAN}

Tabel 1. Distribusi karakteristik responden pada Penyuluh Kesehatan Masyarakat di Kota Parepare

\begin{tabular}{|c|c|c|}
\hline Karakteristik responden & Frekuensi & Persen \\
\hline $\begin{array}{l}\text { Jabatan fungsional } \\
\text { Promkes } \\
\text { Penyuluh } \\
\text { Perawat } \\
\text { bidan }\end{array}$ & $\begin{array}{c}13 \\
13 \\
3 \\
2\end{array}$ & $\begin{array}{c}41,9 \\
41,9 \\
9,7 \\
6,5\end{array}$ \\
\hline $\begin{array}{l}\text { Umur } \\
\text { 26-35 tahun } \\
36-55 \text { tahu n }\end{array}$ & $\begin{array}{l}21 \\
10\end{array}$ & $\begin{array}{l}67,7 \\
32,3\end{array}$ \\
\hline $\begin{array}{l}\text { Jenis kelamin } \\
\text { Laki-laki } \\
\text { perempuan }\end{array}$ & $\begin{array}{c}4 \\
27\end{array}$ & $\begin{array}{l}12,9 \\
87,1\end{array}$ \\
\hline $\begin{array}{l}\text { Pendidikan terakhir } \\
\text { S2 } \\
\text { S1 } \\
\text { D3 }\end{array}$ & $\begin{array}{c}1 \\
27 \\
3\end{array}$ & $\begin{array}{c}3,2 \\
87,1 \\
9,7\end{array}$ \\
\hline $\begin{array}{l}\text { Lama kerja } \\
1-5 \text { tahun } \\
6-10 \text { tahun } \\
>10 \text { tahun } \\
\end{array}$ & $\begin{array}{c}8 \\
14 \\
9 \\
\end{array}$ & $\begin{array}{l}25,8 \\
45,2 \\
29,0 \\
\end{array}$ \\
\hline Total & 31 & 100,0 \\
\hline
\end{tabular}

Sumber : Data Primer, 2018

Tabel 2. Distribusi analisis variabel penelitian pada Penyuluh Kesehatan Masyarakat di Kota Parepare

\begin{tabular}{|c|c|c|}
\hline Variabel & Frekuensi & Persen \\
\hline \multicolumn{3}{|l|}{ Tingkat pengetahuan } \\
\hline $\begin{array}{l}\text { Tinggi } \\
\text { Rendah }\end{array}$ & 24 & $\begin{array}{l}77,4 \\
226\end{array}$ \\
\hline \multicolumn{3}{|l|}{ Keterampilan } \\
\hline Tinggi & 25 & 80,6 \\
\hline Rendah & 6 & 19,4 \\
\hline \multicolumn{3}{|l|}{ Cakupan program } \\
\hline $\begin{array}{l}\text { Tinggi } \\
\text { Rendah }\end{array}$ & $\begin{array}{c}23 \\
8\end{array}$ & $\begin{array}{l}74,2 \\
25,8\end{array}$ \\
\hline Total & 31 & 100,0 \\
\hline
\end{tabular}

Sumber : Data Primer, 2018 
Tabel 3. Pengaruh tingkat pengetahuan penyuluh kesehatan masyarakat terhadap pelaksanaan cakupan program promosi kesehatan

\begin{tabular}{llllllll}
\hline \multirow{2}{*}{$\begin{array}{c}\text { Tingkat } \\
\text { pengetahuan }\end{array}$} & \multicolumn{2}{c}{ Tinggi } & \multicolumn{2}{c}{ Rendah } & Total & \% & P \\
\cline { 2 - 5 } & $\mathbf{N}$ & $\mathbf{\%}$ & $\mathbf{N}$ & $\mathbf{\%}$ & & & \\
\hline Tinggi & 20 & 86.10 & 4 & 50 & 24 & 77.4 & \\
Rendah & 3 & 13.04 & 4 & 50 & 7 & 22.6 & 0,053 \\
\hline Total & $\mathbf{2 3}$ & $\mathbf{1 0 0}$ & $\mathbf{8}$ & $\mathbf{1 0 0}$ & $\mathbf{3 1}$ & $\mathbf{1 0 0}$ & $\mathbf{0 , 0 5 3}$ \\
\hline
\end{tabular}

Sumber : Data Primer, 2018

Tabel 4. Pengaruh keterampilan penyuluh kesehatan masyarakat terhadap pelaksanaan cakupan program promosi kesehatan

\begin{tabular}{|c|c|c|c|c|c|c|c|}
\hline \multirow{3}{*}{ Keterampilan } & \multicolumn{4}{|c|}{ Cakupan program } & \multirow{3}{*}{ Total } & \multirow{3}{*}{$\%$} & \multirow{3}{*}{$\mathbf{P}$} \\
\hline & \multicolumn{2}{|c|}{ Tinggi } & \multicolumn{2}{|c|}{ Rendah } & & & \\
\hline & $\mathbf{N}$ & $\%$ & $\mathbf{N}$ & $\%$ & & & \\
\hline Tinggi & 23 & 100 & 2 & 25 & 25 & 80.6 & \\
\hline Rendah & 0 & 0 & 6 & 75 & 6 & 19.4 & 0,000 \\
\hline Total & 23 & 100 & 8 & 100 & 31 & 100 & $\mathbf{0 , 0 0 0}$ \\
\hline
\end{tabular}

Sumber : Data Primer, 2018 